\title{
Comparing Project Performance of Design-Build and Design-Bid-Build Methods for Large-sized Public Apartment Housing Projects in Korea
}

\author{
Hye-Sung Park ${ }^{1}$, Donghoon Lee ${ }^{2}$, Sunkuk Kim³ ${ }^{3}$, and Jin-Lee Kim*4 \\ ${ }^{1}$ Ph.D. Candidate, Department of Architectural Engineering, Kyung Hee University, Korea \\ ${ }^{2}$ Ph.D. Candidate, Department of Architectural Engineering, Kyung Hee University, Korea \\ ${ }^{3}$ Professor, Department of Architectural Engineering, Kyung Hee University, Korea \\ ${ }^{4}$ Associate Professor, Department of Civil Engineering and Construction Engineering Management, California State University, U.S.A.; \\ International Scholar, Department of Architectural Engineering, Kyung Hee University, Korea
}

\begin{abstract}
The project delivery method has a great impact on project performance and construction quality. The numerous studies on the project performance of the two project delivery methods, design-bid-build (DBB) and design-build (DB), have found differing results depending on the project locations, the project types, and the project sizes. Since no previous studies have been conducted with regard to large-sized apartment housing projects, this paper presents the comparative analysis results for the project performance of the DB and DBB methods, focusing on the large-sized public apartment housing projects built in Korea. The project performances considered include cost, cost growth, construction duration, construction duration growth, and quality performance. The cost and schedule performance analysis results show that the cost growth of the DB method is about 5\% lower than that of the DBB method and the construction duration is shortened by twelve days per floor. The quality performance analysis results demonstrate that the satisfaction with the DB method is higher in terms of the construction quality and efficiency of the DB method. This paper contributes to the growing body of research into the efficiency of project delivery methods, expanding the body of knowledge for large-sized public apartment housing projects.
\end{abstract}

Keywords: project delivery; design-build; design-bid-build; construction management; project performance

\section{Introduction}

The selection of a project delivery method greatly affects the successful completion of project design and construction. Based on questionnaires completed by construction clients and contractors, the project delivery method has a close or extremely close relation with final construction results (Kim et al. 2000). Project delivery methods can be generally classified into design-bid-build (DBB) or design-build (DB) types. These two methods are the most typical methods applied in a variety of countries (Ling and Kerh 2004), although other project delivery methods are available for construction projects. The DB

*Contact Author: Jin-Lee Kim, Ph.D., P.E., LEED AP BD+C, USGBC Faculty, Associate Professor,

Department of Civil Engineering and Construction Engineering Management, California State University, 1250 Bellflower Blvd., Long Beach, U.S.A.

International Scholar, Department of Architectural Engineering,

Kyung Hee University, Gyeonggi-do, Korea

Tel: +1-562-985-1679 Fax: +1-562-985-2380

E-mail: jinlee.kim@csulb.edu

(Received October 7, 2014 ; accepted March 6, 2015) method is a collective design-build bidding, whereas the DBB method is a bidding in which design and build are separated. The construction costs and scopes vary, depending on the project delivery method. The construction cost of the DB method includes the design cost, the construction cost, the model house cost, and so forth. A bidder designs and proposes a building that satisfies the owner's project requirements. Since a contractor participates in the bid process with a designer, it is possible to develop a design that takes into account the constructability and cost of a building. However, it may be difficult to realize an artistic and original design that may be pursued by a designer. In contrast, when using the DBB method, public agencies order a design separately, which makes it easier to reflect the opinions of a client and a designer can come up with an original and creative design. However, it is difficult to predict and manage construction costs. Therefore, one of the intended contributions of this paper is to conduct an accurate cost analysis by comparing the actual construction costs between the DB method and the DBB method, excluding design and model home costs. 
The numerous studies on the project performance of utilizing these two project delivery methods have found differing results based on the project locations, the project types, and the project sizes. From thorough review of the relevant literature, the writers of this paper identified that no studies are available regarding large-sized apartment housing projects. When included, apartment housings have been analyzed together with other project types which have made it difficult to identify the specific characteristics of apartment housing projects. Therefore, this paper examines and analyzes project performance in terms of cost, cost growth, construction duration, and construction duration growth. In addition, it evaluates quality performance through a questionnaire survey with experts who actually perform public housing projects.

\section{Previous Studies}

Although no single project delivery method is most appropriate for any kind of project (Gordon 1994), identifying and applying the most suitable delivery method will be beneficial for project owners when selecting which method best fits for a given type of construction project. Several studies have presented different findings in favor of the DBB method for certain aspects of project performances. Ibbs et al. (2003) compared the traditional DBB and the DB project delivery methods. They examined the relationship between impacts on project change by applying these two project delivery methods while using cost, schedule, and productivity as performance data. They found that the DB method did not perform better than the DBB method in terms of cost and productivity.

Federal Highway Administration compared project performance between the DBB method and the DB method for highway projects and presented the results in favor of the DBB method for the cost growth, while in favor of the DB method for schedule growth (USDOT-FHwA 2006). Shrestha et al. (2007) conducted a statistical analysis for comparing the project performance of the DB method and the DBB method for highway projects. They found that the DB method has a lower schedule growth and a higher cost growth than the DBB method. Another recent study compared project performance of the DB method and the DBB method for industrial projects with cost and schedule in relation with change orders. The statistical analysis showed that timesaving is a definitive benefit for using the DB method, but the benefits in cost savings are debatable (Ohanesian et al. 2013).

On the other hand, numerous studies have been conducted to advocate the use of the DB method over the DBB method. Roth (1995) presented an empirical analysis of United States Navy design-build contracts and found that cost growth for the DB method was lower than that for the DBB method. Songer and Molenaar (1996) discussed owners' attitudes toward the DB method and identified DB selection factors such as establishing cost, reducing cost, establishing schedule, shortening duration, reducing claims, large project size and complexity, and constructability and innovation. Konchar and Sanvido (1998) analyzed the relationship between schedule-cost changes and the type of implemented project delivery method, and found that the DBB method was $11.4 \%$ more likely to suffer changes in schedule than the DB method during the design and construction process. However, it is difficult to discern the characteristics of a specific type of project because building type was not restricted.

Molenaar et al. (1999) analyzed results from 104 completed DB projects in order to provide a DB benchmark for public-sector agencies. Ling et al. (2004) conducted a study on predicting the performances of the DB method and the DBB method. The study discussed the cost and the construction duration of projects implemented in the United States. Ling and Kerh (2004) compared the performances of the DB method and the DBB method employed in Singapore. Warne (2005) assessed the project performance of the DB contracting for highway projects and found that the DB method provides the benefits with aheadof-schedule and reduced cost growth. Hale et al. (2009) compared the performances of the DB method and the DBB method in various ways, including the construction cost, duration, and quality, based on the data of a completed project ordered by the Naval Facilities Engineering Command which differs from this study's scope. They found that the DB method was better than the DBB method in terms of construction duration and cost growth, and estimated that the DB method was better in other evaluation items but that differences were not statistically significant.

Other related studies include a regression analysis for optimal selection of the DB method (Molenaar et al. 1999), DB evaluation (Schaufelberger 2005), selection method (El Asmar et al. 2010), problems and risk (Nurhajar 2009, Molenaar et al. 2000), impact factors of DB-based industrial buildings (Rowlinson 1988), compensation of DB projects in the field of transport (Gransberg and Senadheera 1999), a turn-key related study (Stager 1996), a design and build solution (Friedlander 1998), and a study on the strategy for use of the DB system dynamics model (Park et al. 2009).

Henry and Brothers (2001) analyzed the cost of the simplified acquisition of base engineering requirements (SABER) compared with the cost of the DBB method. SABER is an indefinite delivery, indefinite quantity (IDIQ) agreement in which the prioritized contract is completed and then random projects of the next tasks are completed. Thomas et al. (2002) analyzed the performance of the DB method and the DBB method for projects implemented in the United States, including cost, schedule, safety, changes, rework, and practice use. However, the study did not separate public projects from private projects. 
Al and Mohammed (2002) conducted a study on selecting the most suitable delivery method using the analytic hierarchy process (AHP) for the DB, DBB, and $\mathrm{CM}$ methods. In addition, regional studies have been conducted on the analysis and assessment of DB characteristics in South Africa (Grobler 1999), England (Moore and Dainty 2001), and Hong Kong (Chan et al. 2001). A few recent studies have been conducted to present the current demand and supply situations and customer satisfaction results regarding apartment housing markets in Korea (Choi and Cho 2014, Lee et al. 2014).

These previous studies have different scopes of project types and sizes, but do not provide accurate results for large-sized apartment housing projects. Therefore, the objective of this study is to compare the project performance of the DB and DBB project delivery methods in order to examine the efficiency of these two methods, and to prove which delivery method is superior in terms of cost, schedule, and quality measures for large-sized apartment housing projects.

\section{Research Methodology}

This paper targets large-sized apartment housing projects in order to compare the project performances such as cost, schedule, and quality between the DB method and the DBB method. Since other types of projects such as small-sized apartment housing projects and building projects for different use could lower the reliability of this study, the authors limited the scope of this paper to the large-sized apartment housing projects in Korea, which have the following characteristics: First, the construction cost is at least $\$ 50$ million and the building has at least 20 floors. Second, these residential buildings have little differences by household or by project. Third, the aesthetic requirements are sensitive to the construction quality, such that the exterior design and the quality of finishes are strongly considered in order to satisfy the majority of customers. In addition, the Korean public agencies deliberate a bidding process for large-sized apartment housing projects of more than $\$ 30$ million. It is common practice to use the DBB method for most apartment housing projects unless the projects are either high-rise apartment housing projects of 50 floors or more or there is a need to reduce the construction duration due to the limited project development period.

Public Urban Development Enterprises, a branch of a Korean governmental agency, implements projects to increase public interest, such as building infrastructural facilities, preparing housing sites, and supplying public housing in order to stabilize public residence. Most apartment housing projects ordered by the Public Urban Development Enterprise are large, with similar sites and building designs. Since only companies verified for their design and construction capabilities can participate in the project, which costs at least
$\$ 50$ million, there is less risk in terms of cost and construction duration. Such projects are less impacted by other variables, which can be useful in verifying the differences of the delivery methods.

This paper was carried out in three parts: First of all, the project performance data such as project cost, cost growth, construction duration, and construction duration growth were collected from the Apartment Housing Project Department of Metropolitan Enterprises within the Public Urban Development Enterprise and filtered against the criteria of large-sized apartment housing projects that cost $\$ 50$ million or more. Secondly, the authors conducted a questionnaire survey for the efficiency of project progress and the satisfaction of construction quality from the clients' perspective. Finally, the authors statistically analyzed the verified data to present the analysis findings, followed by conclusions and future studies.

\subsection{Data Collection}

\subsubsection{Cost and Schedule Performance Data}

In order to enhance the reliability of study results, the authors filtered the data collected from the Public Urban Development Enterprises based on five criteria. First, the project cost is at least $\$ 50$ million. Second, the projects include apartment housing without roads, parks, fitness centers, and so forth. Third, the authors only include projects ordered by the Public Urban Development Enterprises between 2004 and 2010 when their construction cost indexes per year are available. Fourth, the projects are limited to buildings with structural and finishing designs highly related to their construction. Finally, the project areas are limited to metropolitan cities with populations of one million or more people. The authors collected data from a total of 37 projects. Among them, the authors excluded six projects that included parks, roads, fitness centers, and so forth (16.2\%), as well as four projects (10.8\%) that cost less than $\$ 50$ million. These projects were excluded from the analysis because such projects show large gaps in cost and construction duration which could distort the study results. Therefore, a total of 27 projects are used for the project cost and schedule performance analysis.

Each floor of the DB projects consists of three to four dwelling units and an elevator shared by occupants. The buildings are built with a reinforced concrete structure comprising an outdoor balcony, three bedrooms, a living room, two bathrooms, and a dining room. Similar to the DB projects, the floor of the DBB projects consists of three to four dwelling units and an elevator shared by occupants. The buildings are built with a reinforced concrete structure comprising an outdoor balcony, four bedrooms, a living room, two bathrooms, and a dining room. Although the designs of the projects are not identical, all the projects are apartment housings with similar structures and layouts. The type of finish work significantly impacts on the cost and the construction duration of apartment 
housing projects. Most apartment housing in Korea has similar finishes, which include Ondol heating wood floor system and wallpaper with the only differences in the ceilings made from either gypsum or veneer board.

\subsubsection{Quality Performance Data}

Apartment housing projects are delivered to the users with finishes, landscaping, HVAC control system, a security system, and the building structure itself. Thus, a high quality of design and construction is required in addition to economical and efficient aspects of the buildings. A questionnaire survey was conducted to compare the efficiency of the two delivery methods with regard to the quality of projects. The survey was completed by hands-on officials working for the Project Delivery and Management Department from three Urban Development Corporations that provided project data. Table 1. shows the description of the questionnaire, consisting of 18 questions that are each scaled to five points. The questionnaire uses a 5 point scale with the most positive evaluation at 5 points and the most negative evaluation at 1 point. The questions are grouped according to four different measures, which include economic feasibility, project efficiency, design quality, and construction quality.
The unit cost $\left(\mathrm{USD} / \mathrm{m}^{2}\right)$ refers to the construction cost per area and is calculated by dividing the project total cost with the construction area.

The cost growth (\%) is used to examine for any increases in cost due to changes in construction or contract, and it is calculated by dividing the final project cost by the contract cost. Construction duration refers to the time in days from start to end of construction completion. Thus, the total duration is divided by the number of floors to estimate the unit duration (day/floor), and to reflect the building size. The number of floors is the most important parameter in comparing the construction duration for the projects with similar areas per floor and structure.

Several statistical methods are used to analyze project performance data. First, descriptive statistics such as the means, medians, and standard deviations are computed to describe the data distributions. Then, Levene's tests are conducted to determine whether the DB and DBB data have equal variance. A paired dependent-sample $t$-test, which typically consists of a sample of matched pairs of similar units, is conducted to investigate whether there is a significant difference between the project costs upon agreement and upon

Table 1. Description of Questionnaire

\begin{tabular}{|c|c|c|}
\hline Measure & Code & Description \\
\hline \multirow{4}{*}{ Economic Feasibility } & Q1 & Total cost of the project \\
\hline & Q2 & Efficiency of cost management \\
\hline & Q3 & Economic feasibility of design \\
\hline & Q4 & Economic feasibility of construction and maintenance \\
\hline \multirow{6}{*}{ Project Efficiency } & Q5 & Efficiency of project implementation \\
\hline & Q6 & Efficiency of communication between client and contractor \\
\hline & Q7 & Efficiency of communication between client and designer \\
\hline & Q8 & Efficiency of design changes \\
\hline & Q9 & Efficiency of selecting a successful bidder \\
\hline & Q10 & Efficiency of project management (site and construction management) \\
\hline \multirow{4}{*}{ Design Quality } & Q11 & Satisfaction on the external and common part designs \\
\hline & Q12 & Efficiency of the external and common part designs \\
\hline & Q13 & Satisfaction on the interior design \\
\hline & Q14 & Efficiency of the interior design \\
\hline \multirow{4}{*}{ Construction Quality } & Q15 & Satisfaction on construction quality \\
\hline & Q16 & Frequency of defect occurrences \\
\hline & Q17 & Satisfaction on responding to defects (defect processing) \\
\hline & Q18 & Satisfaction of occupants \\
\hline
\end{tabular}

\section{Comparative Analysis and Findings}

This section compares project performance between the DB method and the DBB method and presents its findings. Since the projects are all ordered by the Public Urban Development Enterprise, the financial status and the management capacity of a client, which can impact the construction cost and duration, is removed as a variable. Also, the projects are suitable for a comparison due to their relative stability to evaluate project cost based on three criteria: total cost, unit cost, and cost growth. The total cost refers to all expenses for the given project. The authors classified the total cost into the contract cost and the final cost. completion. The mean values for the DB and DBB projects should be analyzed for each performance. The hypotheses for testing are as follows:

$$
\begin{aligned}
& \mathrm{H}_{\mathrm{o}}: \mu_{\mathrm{DB}}=\mu_{\mathrm{DBB}} \\
& \mathrm{H}_{\mathrm{a}}: \mu_{\mathrm{DB}} \neq \mu_{\mathrm{DBB}}
\end{aligned}
$$

where, $\mu_{\mathrm{DB}}$ is either cost or duration mean of the apartment housing projects applying the DB method, and $\mu_{\mathrm{DBB}}$ is either the cost or duration mean of the apartment housing projects applying the DBB method, respectively. The DB project data is independent from the DBB project data, so the difference is examined 
using an independent-sample $t$-test, which is used when two separate sets of independent and identically distributed samples are obtained in order to compare one from each of the two populations.

\subsection{Cost and Schedule Performance Analysis}

Cost and schedule performance data include the contract amount, completed amount, start time, finish time, total area of the building, and the number of floors for a building. The data are used to calculate the unit duration, unit cost, and cost growth. Table 2. tabulates descriptive statistics for project cost and schedule performances. The 27 projects are broken down into $14 \mathrm{DB}$ projects and $13 \mathrm{DBB}$ projects. The means of construction duration and construction unit duration are shorter for the DB projects than the DBB projects. Although the means for contract amount, completed amount, and unit cost are lower for the DBB projects, the mean cost growth is lower for the DB projects. Unit duration is estimated based on the construction cost per floor and includes the duration for temporary work, earth work, and frame and finish work. in the DBB method is 808.923 . It seems that the DBB method is superior to the DB method because the cost of the DB method may contain contingency to avoid cost growth until completion.

\subsubsection{Cost Growth Comparison}

In order to examine the difference in cost growth, the data from the 27 projects was first converted into the unit cost of the contract amount and the completed amount. The dependent-sample $t$-test was then conducted. The means of the unit costs were $\$ 832.48$ and $\$ 960.96$ for the contract amount and the completed amount, respectively. The $t$-value is -12.81 , and the p-value is 0.0 , demonstrating a significant difference in the contract amount and the completed amount for the 27 projects. The final unit cost increases over the contracted amount when large-sized apartment housing projects are executed. The cost growth rate for the two methods has a mean of 1.13 for the DB method and 1.19 for the DBB method, respectively. The two methods meet the equal variance assumption, and the $p$-value of the test is 0.023 at the confidence level of $95 \%$. It can be concluded that there is a difference in the cost

Table 2. Descriptive Statistics for Project Cost and Schedule Performance

\begin{tabular}{|c|c|c|c|c|c|c|}
\hline \multirow[t]{2}{*}{ Parameter } & \multicolumn{3}{|c|}{$\mathrm{DB}(n=14)$} & \multicolumn{3}{|c|}{$\mathrm{DBB}(n=13)$} \\
\hline & Mean & Std. Deviation & Std. Error Mean & Mean & Std. Deviation & Std. Error Mean \\
\hline Construction duration (days) & 930.857 & 146.807 & 39.236 & 997.615 & 154.992 & 42.987 \\
\hline Unit duration (day/floor) & 37.957 & 8.960 & 2.395 & 50.014 & 11.275 & 3.127 \\
\hline Contract amount (\$) & 137.936 & 63.129 & 16.872 & 117.900 & 39.424 & 10.934 \\
\hline Completed amount (\$) & 154.043 & 67.724 & 18.100 & 140.754 & 49.814 & 13.816 \\
\hline Unit cost (contract, \$) & 854.357 & 79.973 & 21.374 & 808.923 & 110.090 & 30.533 \\
\hline Unit cost (completed, \$) & 961.643 & 68.923 & 18.421 & 960.231 & 119.762 & 33.216 \\
\hline Cost growth $(\%)$ & 1.132 & 0.066 & 0.018 & 1.191 & 0.060 & 0.017 \\
\hline
\end{tabular}

\subsubsection{Cost Comparison}

The cost performance data for the two methods are analyzed based on the contract amount, completed amount, unit cost (contract and completed), and cost growth using a two-tailed $t$-test with a confidence level of $95 \%$. Table 3. tabulates the statistical results of the $t$-test for project cost performance between the two methods. Levene's test results show that, disregarding the contract amount in the completion phase, the remaining amounts meet the equal variance assumption. The test results for the contract amount, completed amount, unit cost for contract amount, and unit cost for completed amount show $p$-values of $0.330,0.569,0.229$, and 0.970 , respectively, with no significant difference at the confidence level of $95 \%$. However, it is notable that the unit cost for contract amount in the DB method is 854.357 whereas the one

Table 3. Statistical Results for Project Cost Performance

\begin{tabular}{lcccc}
\hline \multirow{2}{*}{ Parameter } & \multicolumn{2}{c}{ Levene's Test } & \multicolumn{2}{c}{$t$-test } \\
\cline { 2 - 5 } & $F$-value & $p$-value & $t$-value & $p$-value \\
\hline Contract amount $(\$)$ & 4.927 & 0.036 & 0.997 & 0.330 \\
Completed amount (\$) & 2.535 & 0.124 & 0.577 & 0.569 \\
Unit cost (contract, \$) & 1.413 & 0.246 & 1.234 & 0.229 \\
Unit cost (completed, \$) & 3.837 & 0.061 & 0.038 & 0.970 \\
Cost growth $(\%)$ & 0.176 & 0.678 & -2.421 & 0.023 \\
\hline
\end{tabular}

growth rate between the two methods. The DB method is likely to be more favorable than the DBB method in regards to cost growth. The difference in cost growth rates between the two methods are attributed to the efficiency of the DB method as it allows design changes and better communication among project thresholds. The result is clearly confirmed with the survey result in the Analysis on Efficiency of the Project Operation section.

\subsubsection{Construction Schedule Comparison}

The construction duration of the $\mathrm{DB}$ method has a mean of 930.857 days, and that of the DBB method a mean of 997.615 days. The construction durations per floor are 37.957 and 50.014 for the DB method and the DBB method, respectively. Table 4. tabulates statistical results for project schedule performance. The $p$-value of the construction duration is 0.261 at the confidence level of $95 \%$, showing no significant difference. However, the $p$-value of the construction duration per floor is 0.005 at the confidence level of $95 \%$, showing a significant difference. It can be concluded that the $\mathrm{DB}$ method is more suitable when it comes to the construction duration per floor of apartment housing projects in which the same duration is repeated per floor. 
Table 4. Statistical Results for Project Schedule Performance

\begin{tabular}{lcccc}
\hline \multirow{2}{*}{\multicolumn{1}{c}{ Parameter }} & \multicolumn{2}{c}{ Levene's Test } & \multicolumn{2}{c}{ t-test } \\
\cline { 2 - 5 } & $F$-value & $p$-value & t-value & $p$-value \\
\hline $\begin{array}{l}\text { Total duration (days) } \\
\begin{array}{l}\text { Unit duration } \\
\text { (day/floor) }\end{array}\end{array}$ & 0.014 & 0.906 & -1.149 & 0.261 \\
\hline
\end{tabular}

Except for Efficiency of Communication between Client and Designer (Q7), the means of all question responses for the DB method are higher than those of the DBB method. Specifically, the means of Efficiency of Project Implementation (Q5) and Satisfaction on Responding to Defects (Q17) show the greatest difference of 1.5

Table 5. Descriptive Statistics for Questionnaire Results

\begin{tabular}{|c|c|c|c|c|}
\hline Question & Method & Mean & Std. Dev. & Std. Error Mean \\
\hline \multirow[t]{2}{*}{ Q1 Total cost of the project } & DB & 3.427 & 0.879 & 0.166 \\
\hline & DBB & 3.000 & 0.667 & 0.126 \\
\hline \multirow[t]{2}{*}{ Q2 Efficiency of cost management } & DB & 3.643 & 0.731 & 0.138 \\
\hline & DBB & 2.643 & 0.731 & 0.138 \\
\hline \multirow[t]{2}{*}{ Q3 Economic feasibility of design } & DB & 3.893 & 0.497 & 0.094 \\
\hline & DBB & 2.929 & 0.766 & 0.145 \\
\hline \multirow[t]{2}{*}{ Q4 Economic feasibility of construction and maintenance } & DB & 3.893 & 0.685 & 0.130 \\
\hline & DBB & 2.857 & 0.705 & 0.133 \\
\hline \multirow[t]{2}{*}{ Q5 Efficiency of project implementation } & DB & 4.250 & 0.518 & 0.098 \\
\hline & DBB & 2.571 & 0.742 & 0.140 \\
\hline \multirow[t]{2}{*}{ Q6 Efficiency of communication between client and contractor } & DB & 4.107 & 0.416 & 0.079 \\
\hline & DBB & 2.786 & 0.686 & 0.130 \\
\hline \multirow[t]{2}{*}{ Q7 Efficiency of communication between client and designer } & DB & 3.429 & 0.790 & 0.150 \\
\hline & DBB & 3.500 & 0.839 & 0.159 \\
\hline \multirow[t]{2}{*}{ Q8 Efficiency of design changes } & DB & 3.321 & 1.219 & 0.230 \\
\hline & DBB & 3.071 & 0.858 & 0.162 \\
\hline \multirow[t]{2}{*}{ Q9 Efficiency of selecting a successful bidder } & DB & 3.429 & 1.034 & 0.195 \\
\hline & DBB & 3.179 & 0.863 & 0.163 \\
\hline \multirow[t]{2}{*}{ Q10 Efficiency of project management (site and construction) } & DB & 4.286 & 0.535 & 0.101 \\
\hline & DBB & 2.857 & 0.756 & 0.143 \\
\hline \multirow[t]{2}{*}{ Q11 Satisfaction on the external and common part designs } & DB & 3.714 & 0.763 & 0.144 \\
\hline & DBB & 3.250 & 0.844 & 0.160 \\
\hline \multirow[t]{2}{*}{ Q12 Efficiency of the external and common part designs } & DB & 3.643 & 0.780 & 0.147 \\
\hline & DBB & 3.357 & 0.731 & 0.138 \\
\hline \multirow[t]{2}{*}{ Q13 Satisfaction on the interior design } & DB & 3.893 & 0.629 & 0.119 \\
\hline & DBB & 3.179 & 0.670 & 0.127 \\
\hline \multirow[t]{2}{*}{ Q14 Efficiency of the interior design } & DB & 3.786 & 0.738 & 0.140 \\
\hline & DBB & 3.321 & 0.670 & 0.127 \\
\hline \multirow[t]{2}{*}{ Q15 Satisfaction on construction quality } & DB & 3.964 & 0.576 & 0.109 \\
\hline & DBB & 3.107 & 0.629 & 0.119 \\
\hline \multirow[t]{2}{*}{ Q16 Frequency of defect occurrences } & DB & 3.643 & 0.621 & 0.117 \\
\hline & DBB & 2.643 & 0.621 & 0.117 \\
\hline \multirow[t]{2}{*}{ Q17 Satisfaction on responding to defects (defect processing) } & DB & 3.750 & 0.646 & 0.122 \\
\hline & DBB & 2.250 & 0.646 & 0.122 \\
\hline \multirow[t]{2}{*}{ Q18 Satisfaction of occupants } & DB & 3.929 & 0.539 & 0.102 \\
\hline & DBB & 2.929 & 0.604 & 0.114 \\
\hline
\end{tabular}

\subsection{Quality Performance Analysis}

A total of 28 responses were collected, among which 18 respondents were project managers $(64.3 \%)$, 7 respondents were managers/officers $(25 \%)$, and 3 respondents were engineers $(10.7 \%)$. Also, 12 of them were responsible for contracts $(42.9 \%), 13$ were project managers (46.4\%), and 3 supported the projects $(10.7 \%)$. The questionnaire asked respondents to compare and assess the DB and DBB methods. Thus, the questionnaire results provide the relative values of the two methods.

Table 5. shows the descriptive statistics for questionnaire results; the results show different values. or more. An independent $t$-test and a paired $t$-test are conducted for the questionnaire data on the project results and quality. Table 6. tabulates the statistical results for project quality performance, which includes economic feasibility, efficiency of the project operation, design quality, and construction quality.

\subsubsection{Analysis on Economic Feasibility}

The respondents, who are involved in the apartment housing projects, had clear responses on economic feasibility. It can be concluded that the DB method is superior to the DBB method in terms of Efficiency of Cost Management (Q2), Economic Feasibility of Design (Q3), and Economic Feasibility of Construction 
Table 6. Statistical Result for Project Quality Performance

\begin{tabular}{|c|c|c|c|c|}
\hline Question & DB Mean & DBB Mean & $t$-value & $p$-value (2-tailed) \\
\hline Q1 Total cost of the project & 3.429 & 3.000 & 1.800 & 0.083 \\
\hline Q2 Efficiency of cost management & 3.643 & 2.643 & 4.145 & 0.000 \\
\hline Q3 Economic feasibility of design & 3.893 & 2.929 & 4.247 & 0.000 \\
\hline Q4 Economic feasibility of construction and maintenance & 3.893 & 2.857 & 4.816 & 0.000 \\
\hline Q5 Efficiency of project implementation & 4.250 & 2.570 & 8.705 & 0.000 \\
\hline Q6 Efficiency of communication between client and contractor & 4.107 & 2.786 & 9.053 & 0.000 \\
\hline Q7 Efficiency of communication between client and designer & 3.429 & 3.500 & -0.273 & 0.787 \\
\hline Q8 Efficiency of design changes & 3.321 & 3.071 & 0.697 & 0.492 \\
\hline Q9 Efficiency of selecting a successful bidder & 3.429 & 3.179 & 0.826 & 0.416 \\
\hline Q10 Efficiency of project management (site/construction) & 4.286 & 2.857 & 7.878 & 0.000 \\
\hline Q11 Satisfaction on the external and common part designs & 3.714 & 3.250 & 1.788 & 0.085 \\
\hline Q12 Efficiency of the external and common part designs & 3.643 & 3.357 & 1.216 & 0.234 \\
\hline Q13 Satisfaction on the interior design & 3.893 & 3.179 & 3.873 & 0.001 \\
\hline Q14 Efficiency of the interior design & 3.786 & 3.321 & 2.159 & 0.040 \\
\hline Q15 Satisfaction on construction quality & 3.964 & 3.107 & 4.869 & 0.000 \\
\hline Q16 Frequency of defect occurrences & 3.643 & 2.643 & 5.392 & 0.000 \\
\hline Q17 Satisfaction on responding to defects (defect processing) & 3.750 & 2.250 & 7.937 & 0.000 \\
\hline Q18 Satisfaction of occupants & 3.929 & 2.929 & 5.612 & 0.000 \\
\hline
\end{tabular}

and Maintenance (Q4) based on the two-tailed $t$-test conducted at the confidence level of $95 \%$. Although Q1-Q4 are all related to economic feasibility, however, there is no statistically significant difference in the Total Cost of the Projects (Q1) as cost is generally affected by the design rather than the project delivery method, unlike Efficiency of Cost Management (Q2). 4.2.2 Analysis on Efficiency of Project Operation

A questionnaire survey was used to measure overall operational efficiency from the client's perspective. As a result of the $t$-test on responses as shown in Table 6., the DB method was found to be superior to the DBB method in regards to Efficiency of Project Implementation (Q5), Efficiency of Clientcontractor Communication (Q6), and Efficiency of Site Process Management and Construction Management (Q10). The DBB method reveals better clientdesigner communication because the owner/client directly communicates with the designer. Although the mean of Efficiency of Communication between Client and Designer (Q7) was slightly higher for the DBB method than the DB method, there was no statistically significant difference at the two-tailed $t$-test. In addition, there were no differences in terms of Efficiency of Design Changes (Q8) and Efficiency of Selecting a Successful Bidder (Q9).

\subsubsection{Analysis on Design Quality}

It is difficult to determine design quality because it is a subjective indicator. Therefore, the design is separated by exterior and by interior, and then aesthetic satisfaction and efficiency are classified from these separate categories so that respondents can more easily answer the questionnaire. Here, efficiency refers to the occupant's efficiency, including the occupant's traffic line, parking space, and various housing management systems. Based on the results shown in Table 6., no difference can be found in terms of exterior design. However, it can be concluded that the DB method is

superior to the DBB method in terms of Satisfaction on the Interior Design (Q13) and Efficiency of the Interior Design (Q14). The design quality can be evaluated differently depending on the client's requirements. Nevertheless, the reason why the DB method is superior to the DBB method in design quality is that construction quality is taken into consideration when designing the project.

\subsubsection{Analysis on Construction Quality}

There are four questionnaire items regarding construction quality: Satisfaction of Construction Quality (Q15), Frequency of Defect Occurrences (Q16), Satisfaction of Responding to Defects (Q17), and Satisfaction of Occupants (Q18). As shown in Table 6., the $p$-values are 0.0 , indicating significant differences for all four items. It can be concluded that the project experts believe the DB method is superior to the DBB method in terms of construction quality because the difference in construction quality is subjected to the value of the final product, which fulfills the needs of operation and maintenance cost.

\section{Conclusions}

This paper presented a comparative analysis on the project cost, schedule, and quality performances between the two project delivery methods such as design-bidbuild method and design-build method in order to improve the reliability of analysis results by focusing on large-sized public apartment housing projects while minimizing the variability among projects. The main findings demonstrate that the cost growth of the completed amount against the contract amount for the DB projects represents an increase of $13 \%$, which is less than that of the DBB projects, which is $19 \%$. The project costs of the two methods are significantly different. Difference in overall construction duration cannot be found based on the data; however, the mean construction duration per floor is 37.96 days and 50.01 days for the 
DB method and the DBB method, respectively, showing a significant difference by approximately 12 days per floor. Therefore, the DB method is determined to be favorable in terms of the construction duration per floor.

An 18-question survey regarding the efficiency and construction quality indicates that the DB method is superior to the DBB method in terms of several measures previously mentioned. This paper confirms the differences in project performance according to the delivery methods of large-sized apartment housing projects, and coincides with existing studies that the DB method is superior to the DBB method with respect to several measures.

This paper contributes to research in the efficiency of the two project delivery methods for large-sized apartment housing projects. The study results are useful when selecting a project delivery method for largesized apartment housing projects with a construction cost of at least $\$ 50$ million. However, it is notable that the DB method often leads to an unexpected increase in design cost. Thus, it is important for the design department of a DB firm to have a thorough understanding of drawings and specifications. In addition, the Public Urban Development Enterprises are expected to reduce the risk on the DB firm to avoid its own risk. Future studies are needed to examine the differences in project delivery methods based on different construction project types and scales.

\section{References}

1) Al, K., and Mohammed, I. (2002) Selecting the appropriate project delivery method using AHP. International Journal of Project Management, 20 (6), pp.469-474.

2) Chan, A. P., Ho, D. K., and Tam, C. M. (2001) Design and build: Views from some major public clients in Hong Kong. Australasian Journal of Construction Economics and Building, 1 (1), pp.22-31.

3) Choi, J., and Cho, T. (2014) Comparing perception concerning the importance of apartment complex components between consumers and housing providers. Journal of Asian Architecture and Building Engineering, 13(1), pp.109-116.

4) El Asmar, M., Lotfallah, W., Whited, G., and Hanna, A. S. (2010) Quantitative methods for design-build team selection. Journal of Construction Engineering and Management, 136 (8), pp.904-912.

5) Friedlander, M. C. (1998) FEATURE: Design/build solutions. Journal of Management in Engineering, 14 (6), pp.59-64.

6) Gordon, C. M. (1994) 'Choosing appropriate construction contracting method. Journal of Construction Engineering and Management, 120 (1), pp.196-210.

7) Gransberg, D. D., and Senadheera, S. P. (1999) Design-build contract award methods for transportation projects. Journal of Transportation Engineering, 125 (6), pp.565-567.

8) Grobler, K. (1999) An evaluation of design-build as procurement method for building and civil engineering projects in South Africa. Ph.D. Dissertation, Rand Afrikaans University.

9) Henry, E., and Brothers, H. S. (2001) Cost analysis between SABER and design bid build contracting methods. Journal of Construction Engineering and Management, 127 (5), pp.359-366.

10) Hale, D. R., Shrestha, P. P., Gibson Jr, G. E., and Migliaccio, G. C. (2009) Empirical comparison of design/build and design/bid/build project delivery methods. Journal of Construction Engineering and Management, 135 (7), pp.579-587.

11) Ibbs, C. W., Kwak, Y. H., Ng, T., and Odabasi, A. M. (2003) Project delivery systems and project change: Quantitative analysis. Journal of Construction Engineering and Management, 129 (4), pp.382-387.
12) Kim K. I., Seo Y. C., and Hyun C. T. (2000) A study on the selection criteria for delivery systems in the large public building projects. Journal of Architectural Institute of Korea, 16 (4), pp.7986.

13) Konchar, M., and Sanvido, V. (1998) Comparison of U.S. project delivery systems. Journal of Construction Engineering and Management, 124 (6), pp.435-444.

14) Lee, S., Shin, K., Kim, J., and Kim, J. (2014) Comparison of dynamics in the Korean housing market based on the FDW model for the periods before and after the macroeconomic fluctuations. Journal of Asian Architecture and Building Engineering, 13(1), pp.117-124.

15) Ling, F. Y. Y., and Kerh, S. H. (2004) Comparing the performance of design-build and design-bid-build building projects in Singapore. Architectural Science Review, 47 (2), pp.163-175.

16) Ling, F. Y. Y., Chan, S. L., Chong, E., and Ee, L. P. (2004) Predicting performance of design-build and design-bid-build projects. Journal of Construction Engineering and Management, 130 (1), pp.75-83.

17) Molenaar, K. R., Songer, A. D., and Barash, M. (1999) Publicsector design/build evolution and performance. Journal of Management in Engineering, 15 (2), 54-62.

18) Molenaar, K., Vanegas, J., and Martinez, H. (2000) Appropriate Risk Allocation in Design-Build RFPs. Proc., Construction Research Congress, ASCE, Reston, VA, pp.1083-1092.

19) Moore, D. R., and Dainty, A. R. (2001) Intra-team boundaries as inhibitors of performance improvement in UK design and build projects: A call for change. Construction Management and Economics, 19 (6), pp.559-562.

20) Nurhajar, A. R. (2009) A survey on problem faced by contractors using design and build contract. Ph.D. Dissertation, University Malaysia Pahang.

21) Ohanesian, S., Kim, J.-L., Nguyen, T.-H., and Kim, O.-K. (2013) Quantitative analysis on project performance analysis and delivery methods. Proc., of the Fifth International Conference on Construction Engineering and Project Management, Jan. 9-11, 2013, Anaheim, California, S13, pp.1-6.

22) Park, M., Ji, S. H., Lee, H. S., and Kim, W. (2009) "Strategies for design-build in Korea using system dynamics modeling. Journal of Construction Engineering and Management, 135 (11), pp.11251137.

23) Roth, M. B. (1995) An empirical analysis of United States Navy design/build contracts. Master's thesis, Univ. of Texas at Austin, Tex.

24) Rowlinson, S. M. (1988) An analysis of factors affecting project performance in industrial buildings with particular reference to design build contracts. 〈http://bura.brunel.ac.uk/handle/2438/4320 (Jan. 15, 2014).

25) Schaufelberger, J. E. (2005) Use of design-build on mass transit rail projects. Proc., Construction Research Congress, ASCE, Reston, VA, pp.1-10.

26) Shrestha, P. P., Migliaccio, G. C., O'Connor, J. T., and Gibson, G. E. Jr. (2007) Benchmarking of large design-build highway projects: One to one comparison and comparison with design-bid-build projects. Transportation Research Record , 1994 (1), pp.17-25.

27) Songer, A. D., and Molenaar, K. R. (1996) Selecting design-build: Public and private sector owner attitudes. Journal of Management in Engineering, 124 (6), pp.47-53.

28) Stager, D. K. (1996) Organizing and managing a finance-designbuild project in Turkey: Fourth roebling lecture. Journal of Construction Engineering and Management, 122 (3), pp.199-204.

29) Thomas, S. R., Macken, C. L., Chung, T. H., and Kim, I. (2002) Measuring the impacts of the delivery system on project performance-Design-build and design-bid-build. NIST GCR, 2, 840. 〈http://fire.nist.gov/bfrlpubs/build02/PDF/b02150.pdf 〉 (Dec. $15,2013)$.

30) U.S. Department of Transportation, Federal Highway Administration. (2006) Design-build effectiveness study." 〈http:// www.fhwa.dot.gov/reports/designbuild/designbuild.pdf) (Jan. 15, 2014).

31) Warne, T. R. (2005) Design build contracting for highway projects: A performance assessment. Tom Warne \& Associates, LLC. 